\title{
SUPPLEMENT
}

"Runup, Inundation, and Sediment Characteristics of December 222018 Indonesia Sunda Strait Tsunami” Wahyu Widiyanto et al.

\section{Sand samples}

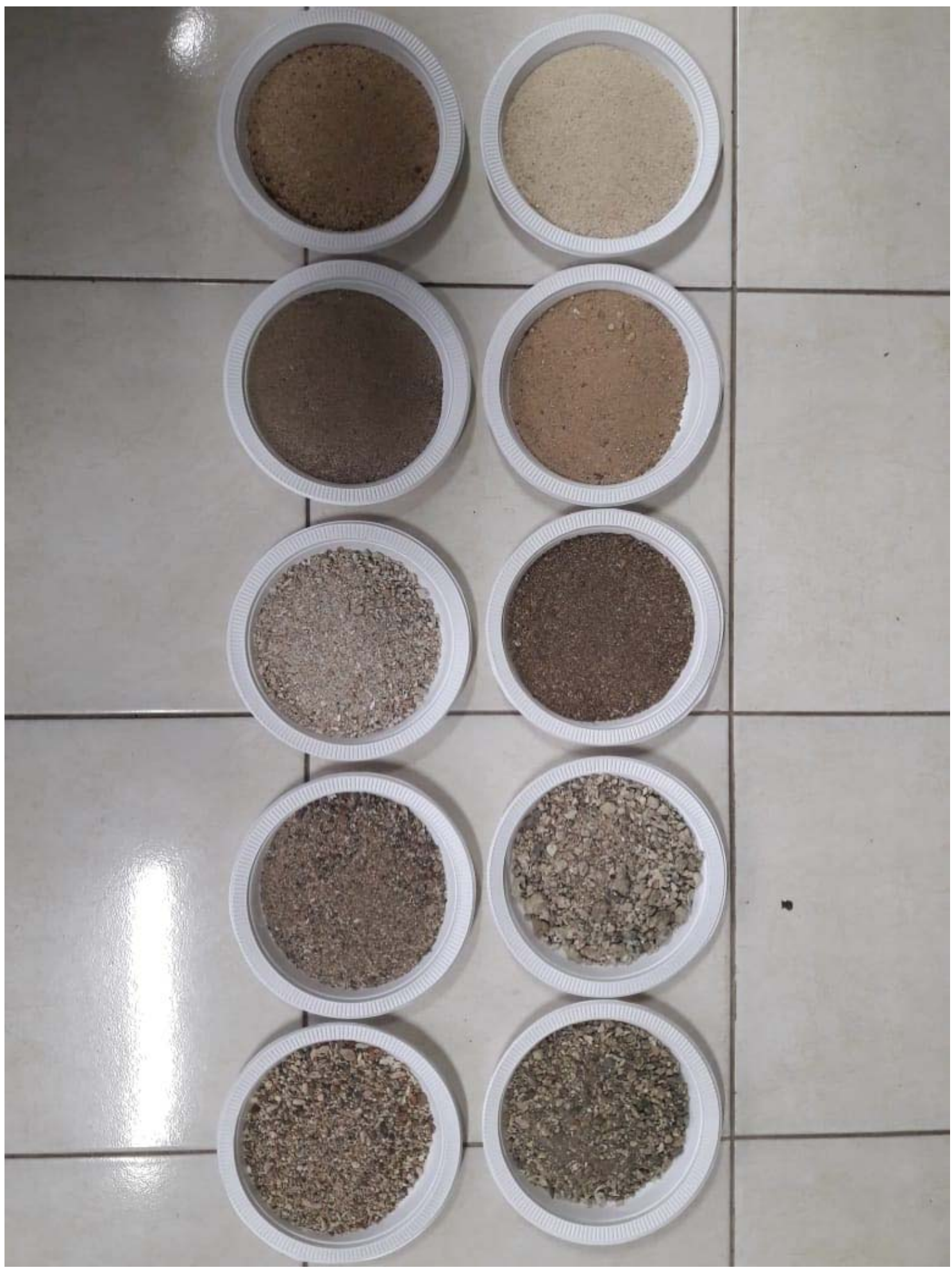



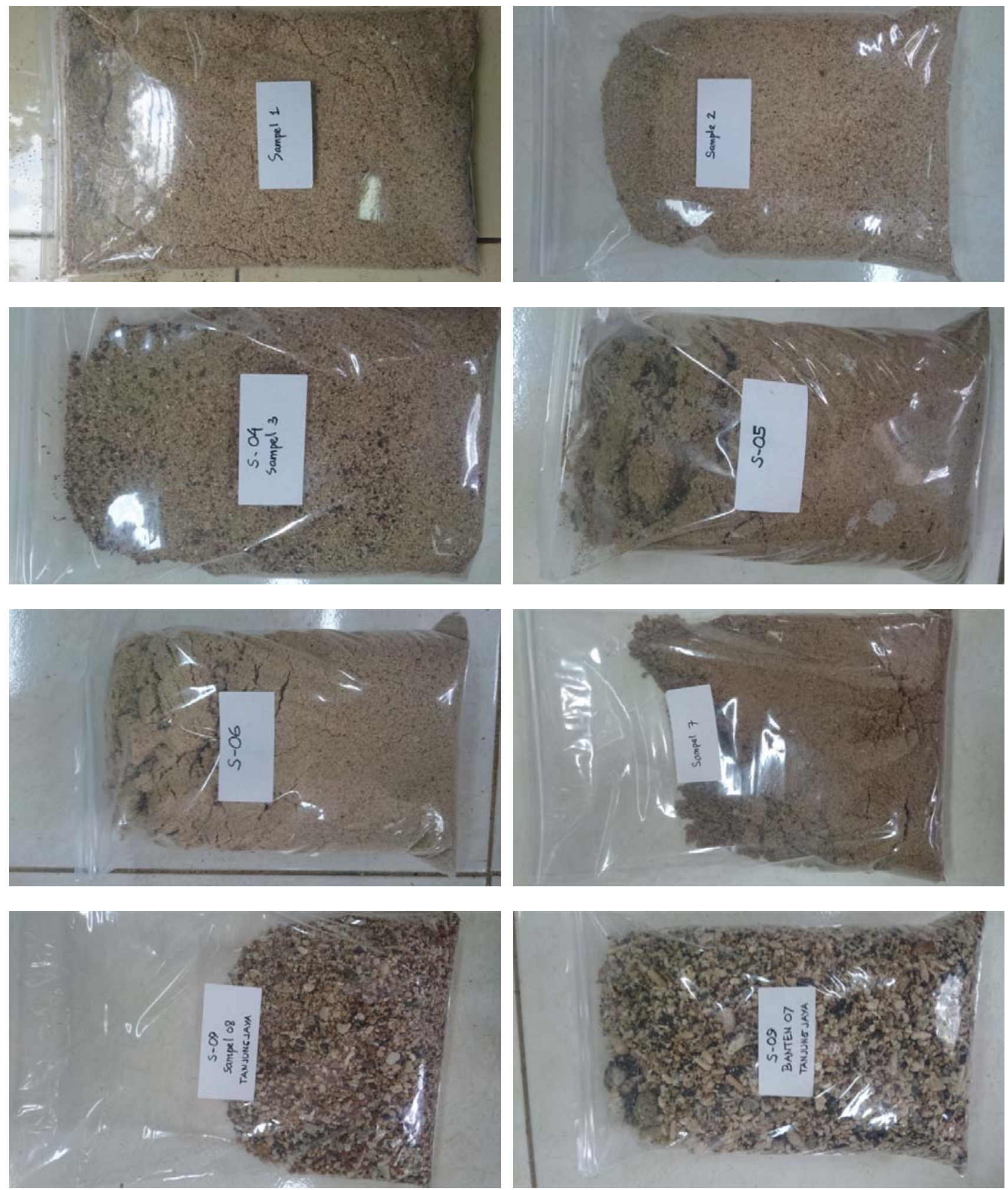

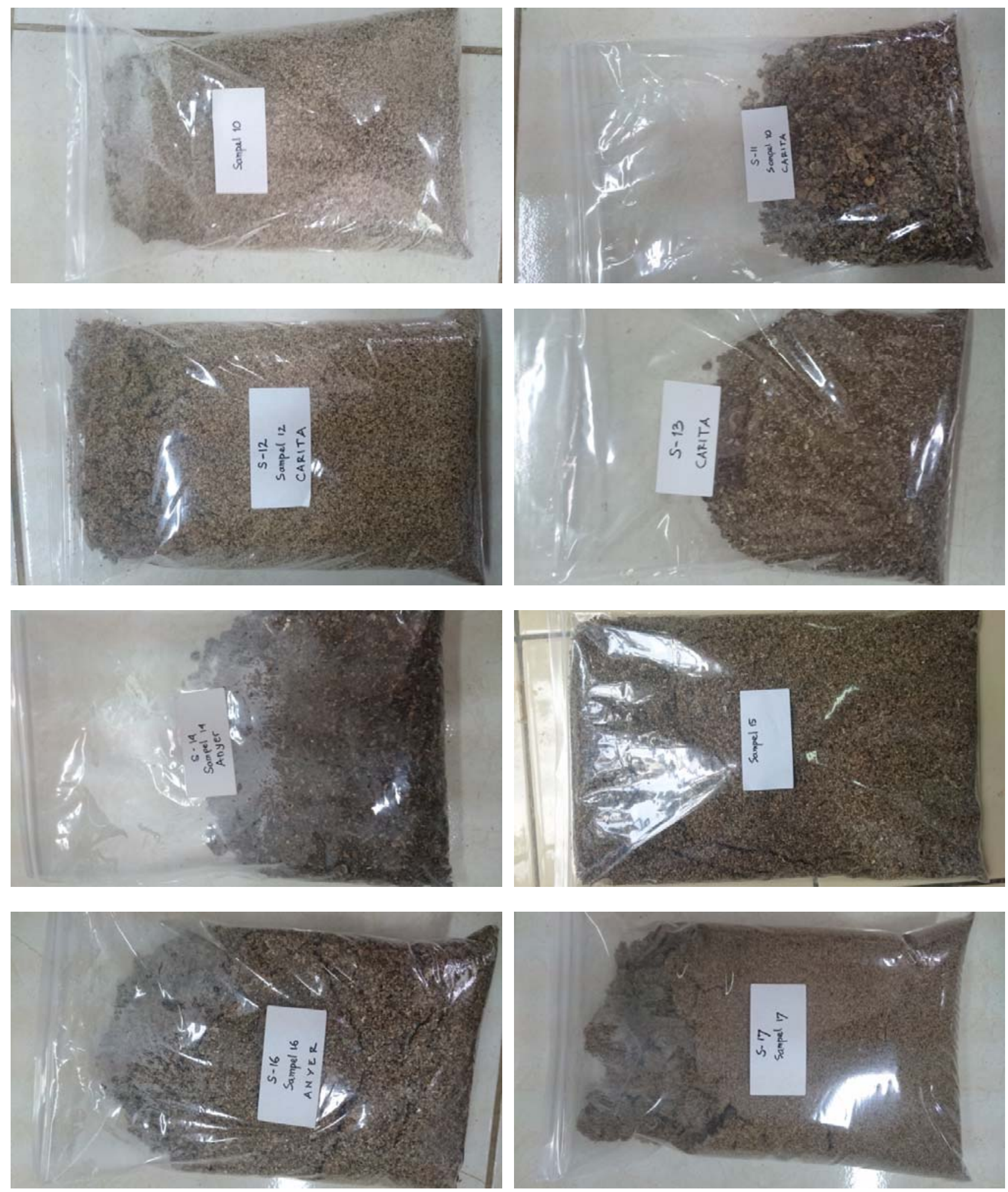

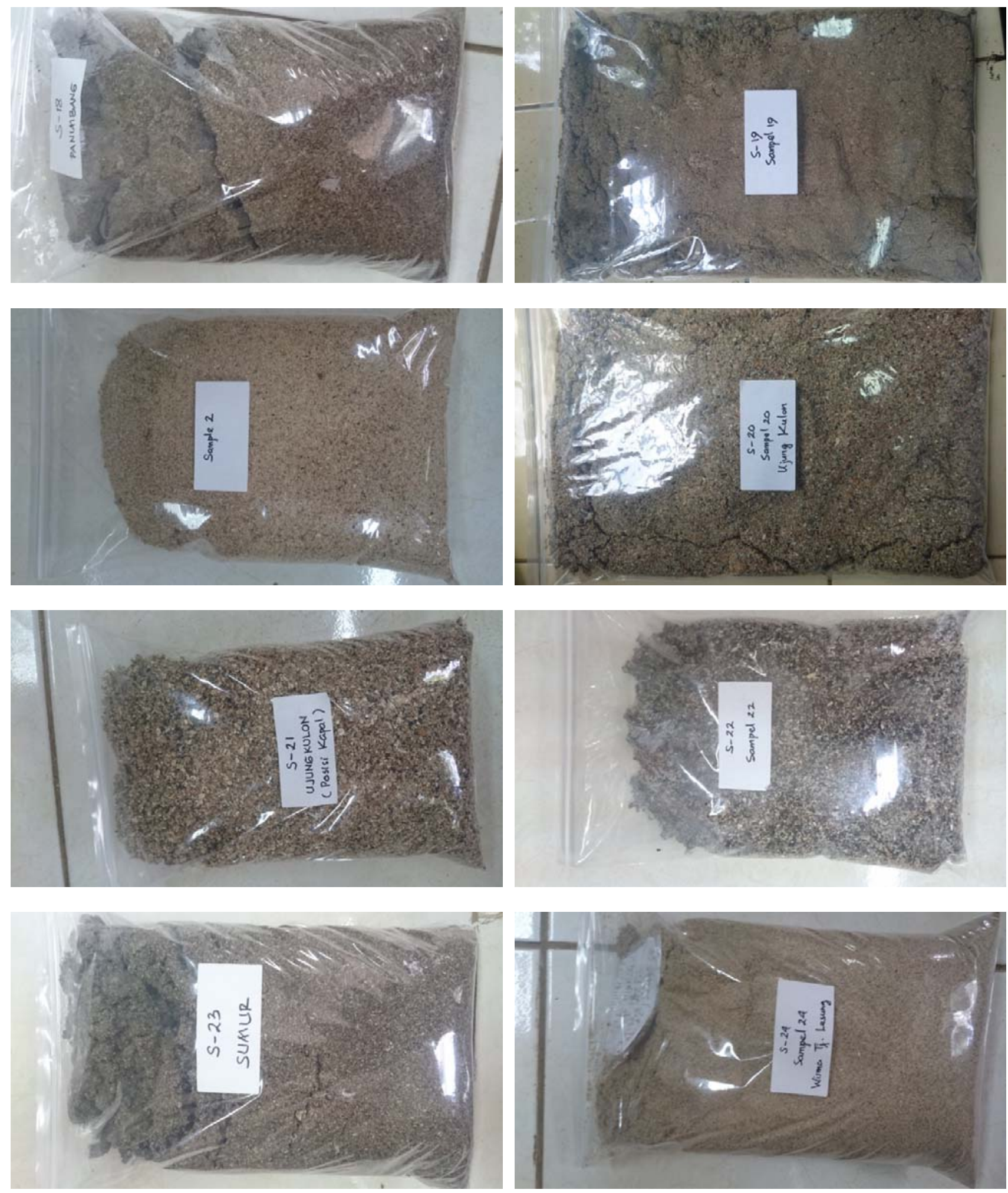

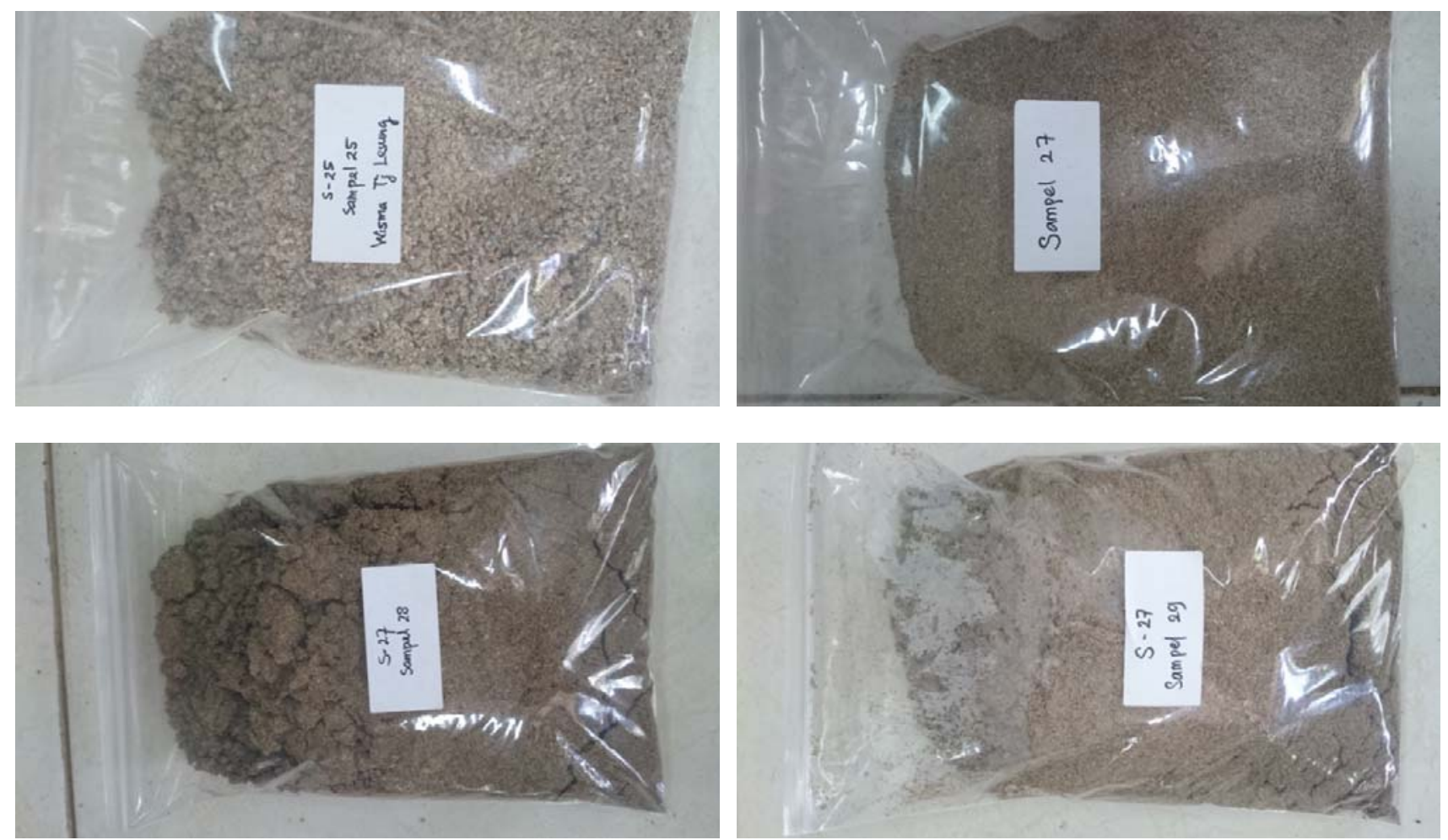

Boulder movement
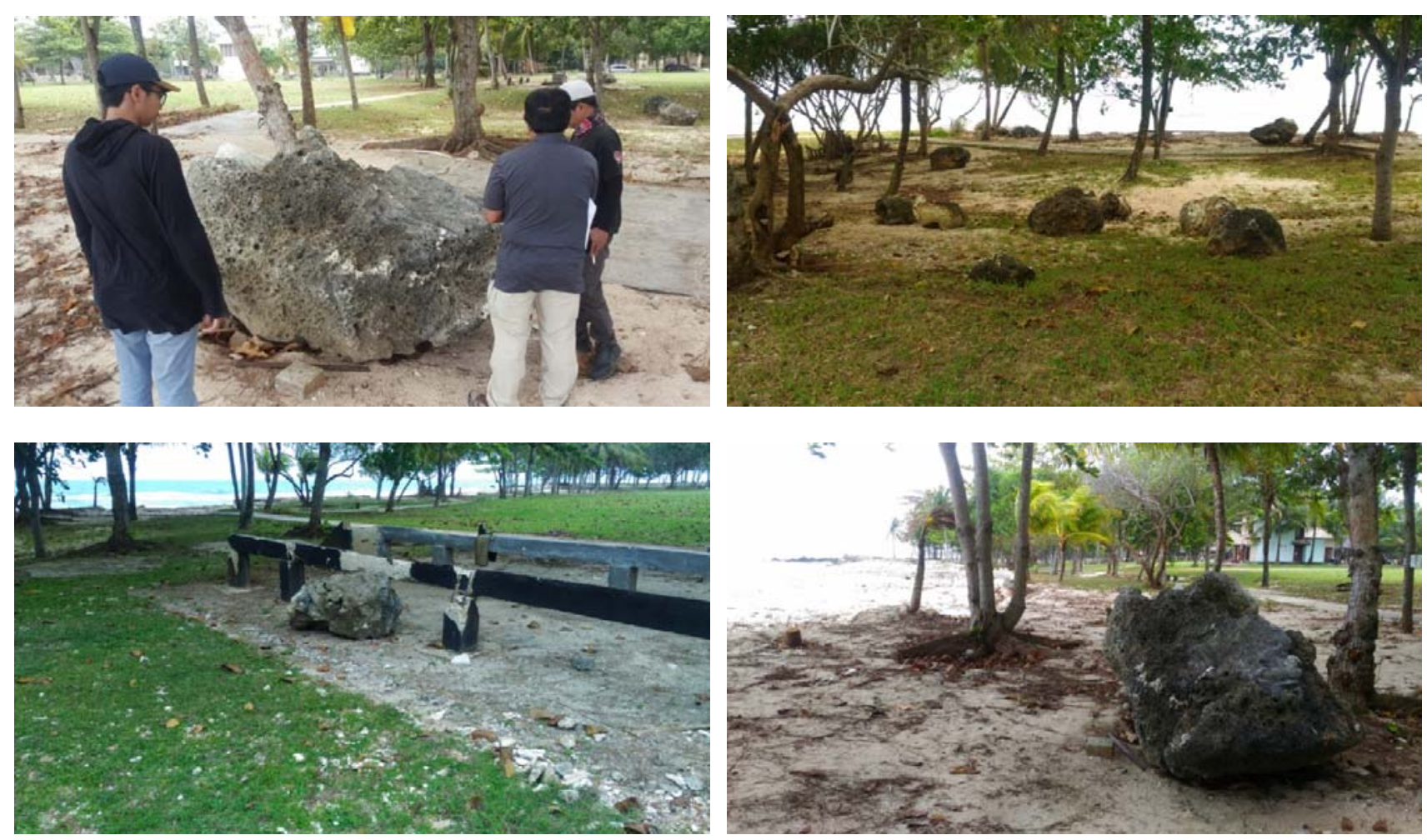

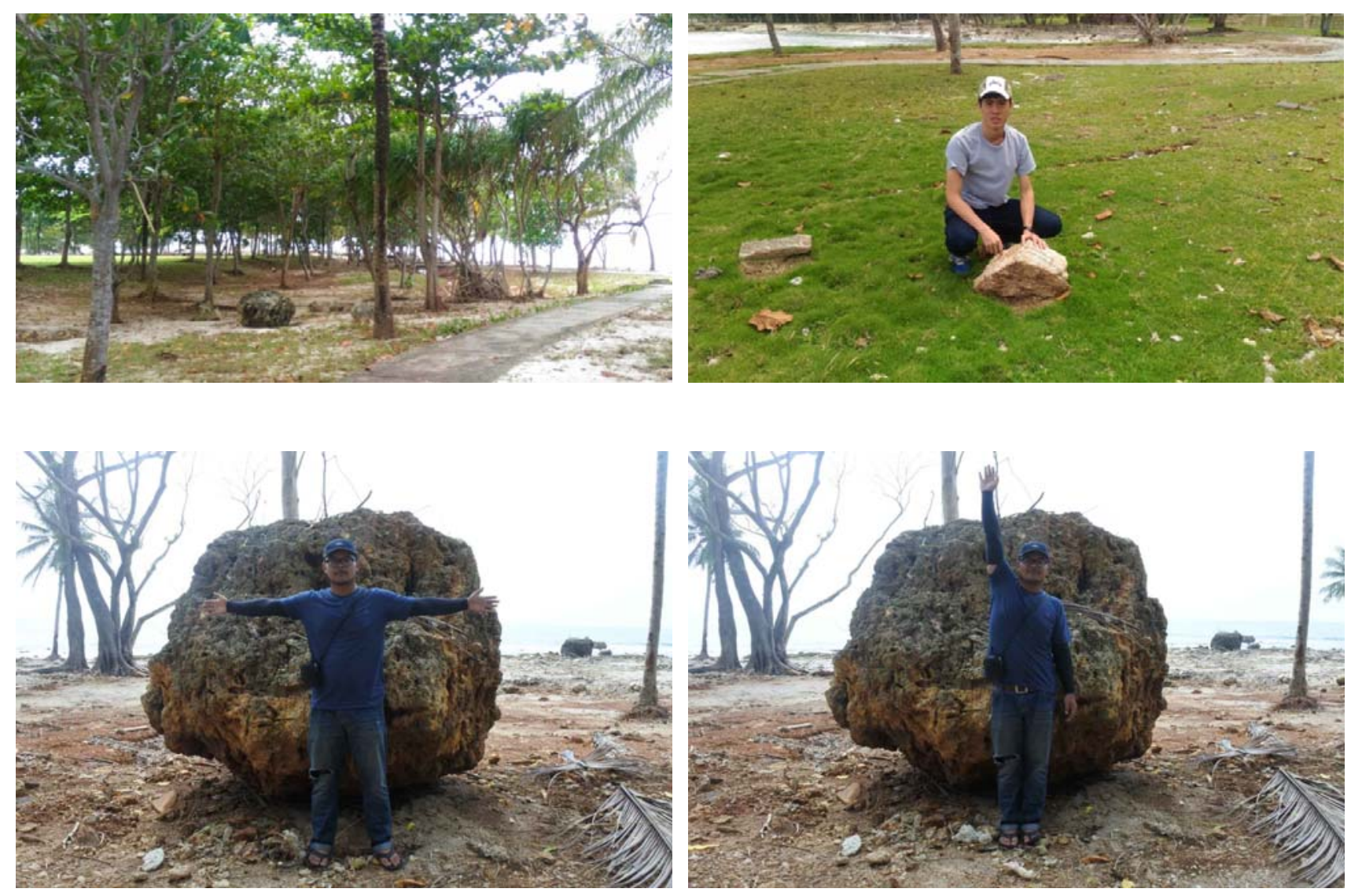

\section{Damages}
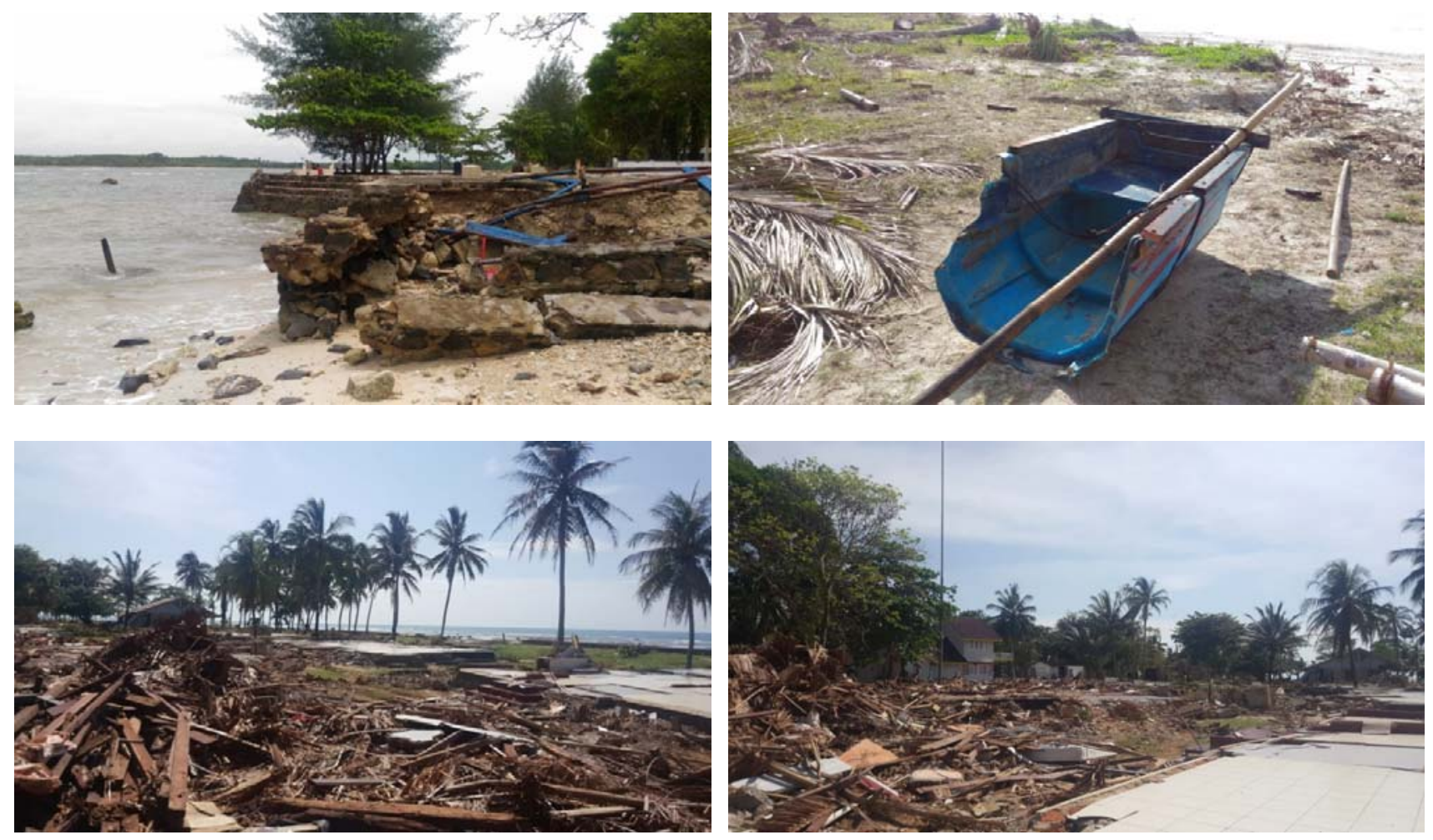

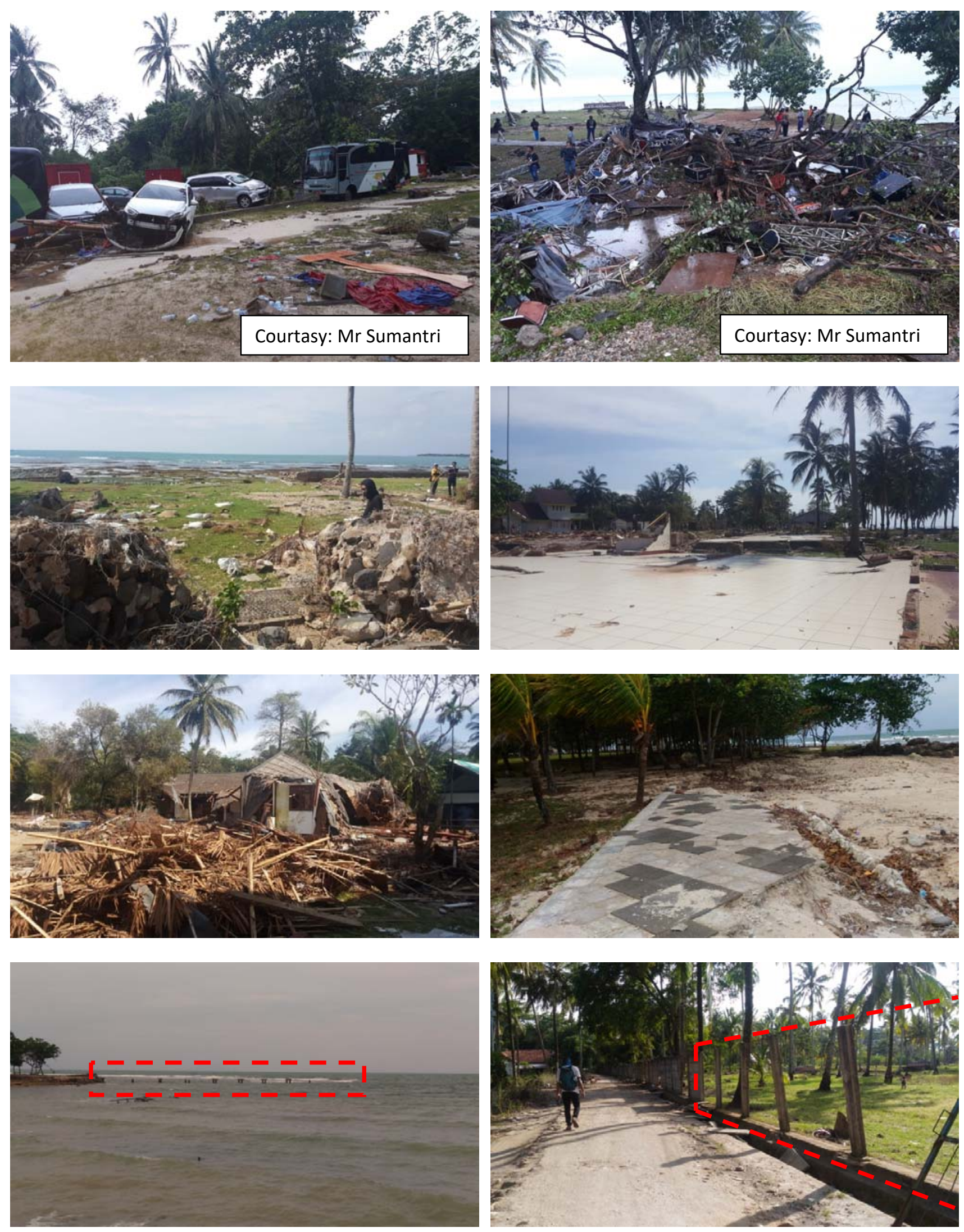

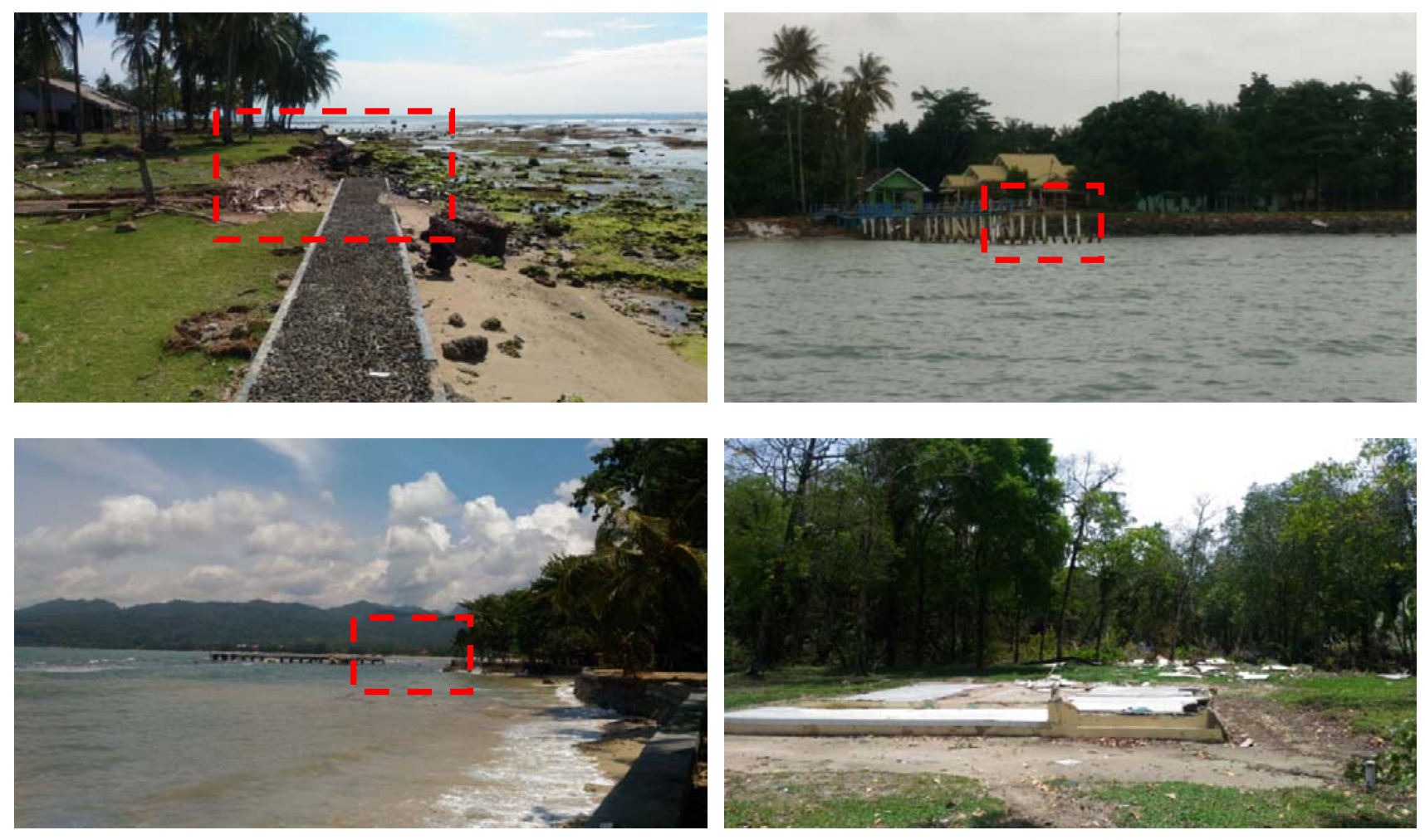

Tsunami direction evidences
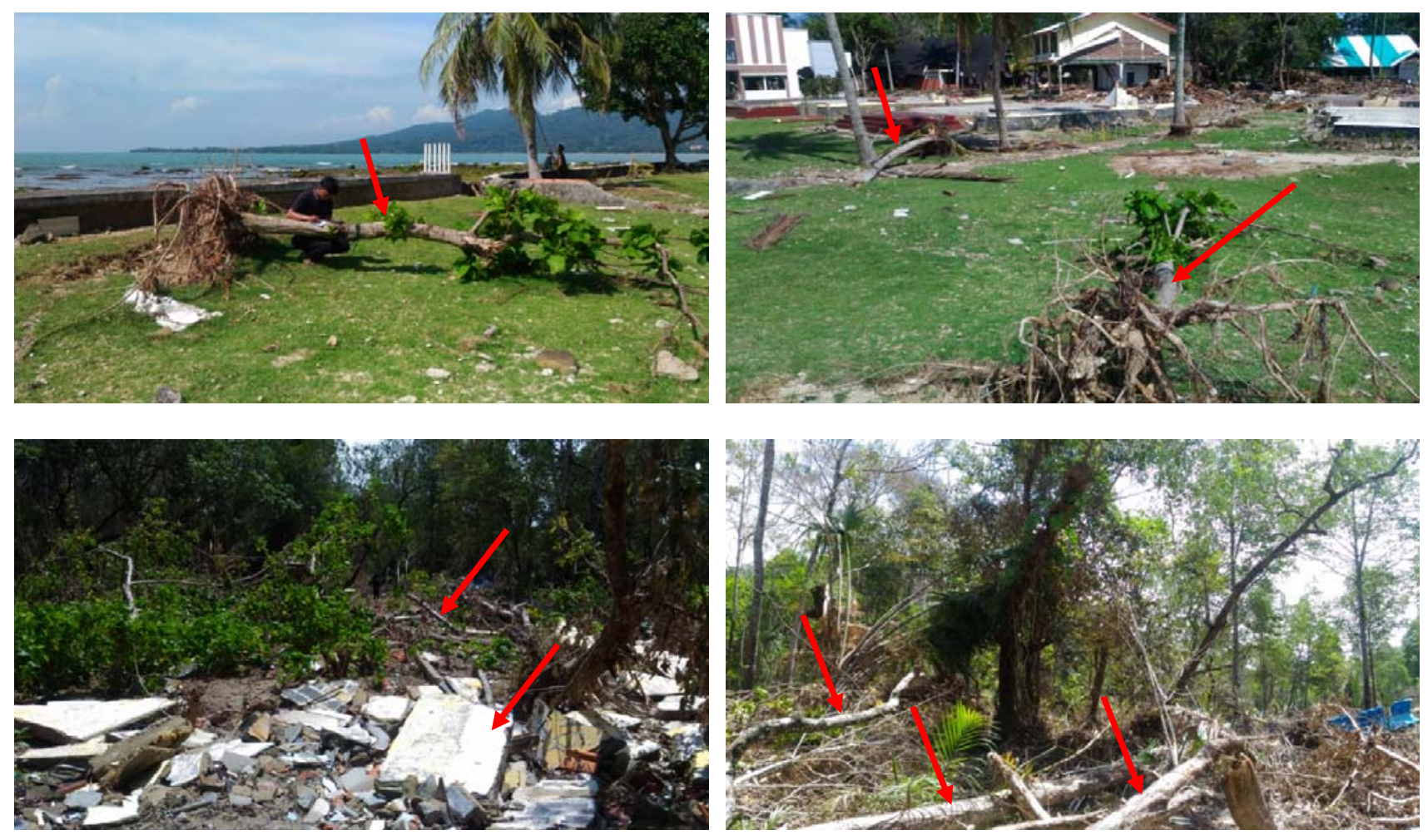

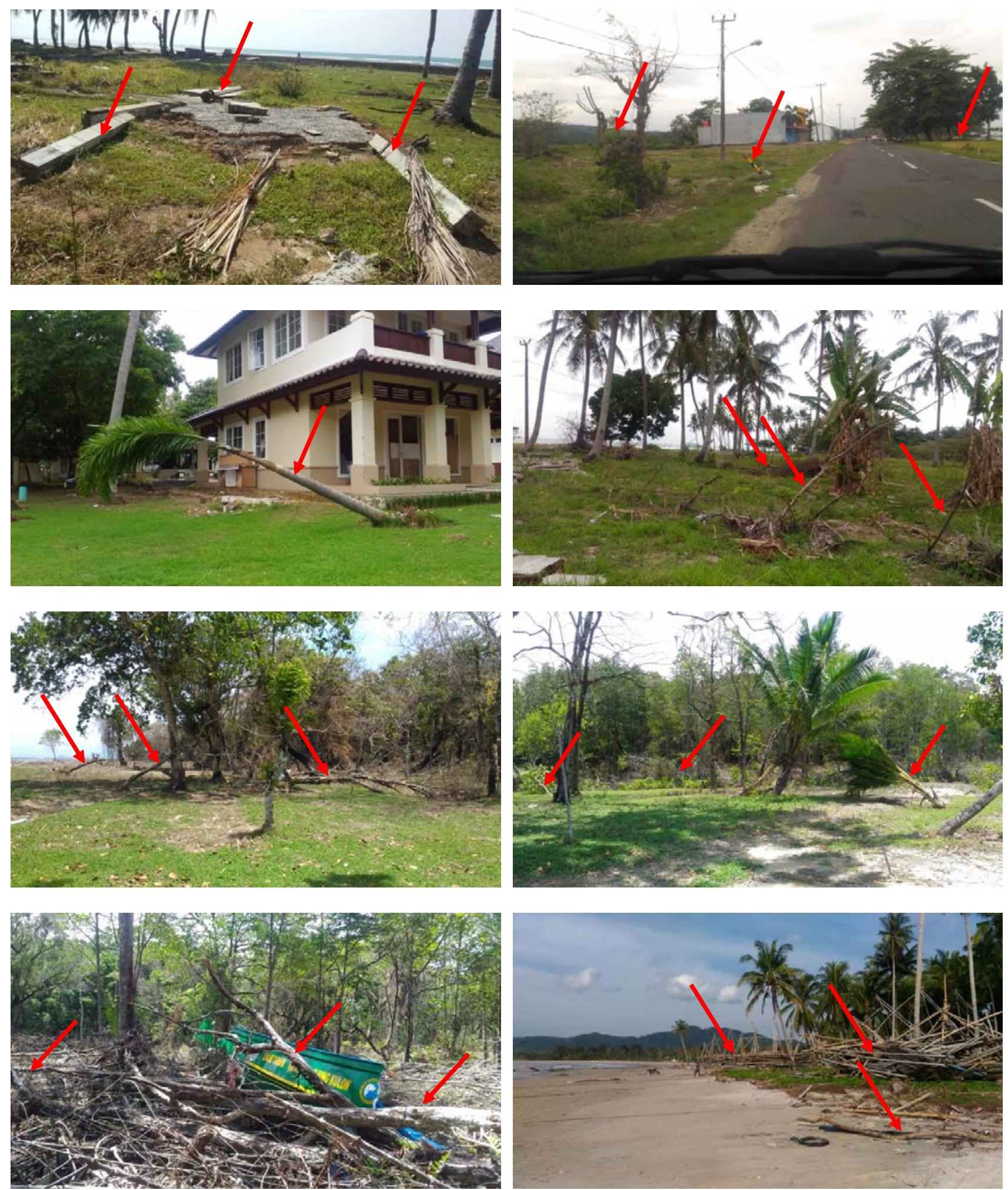
Flow depth and flash evidences (with additional information from eyewitnesses)
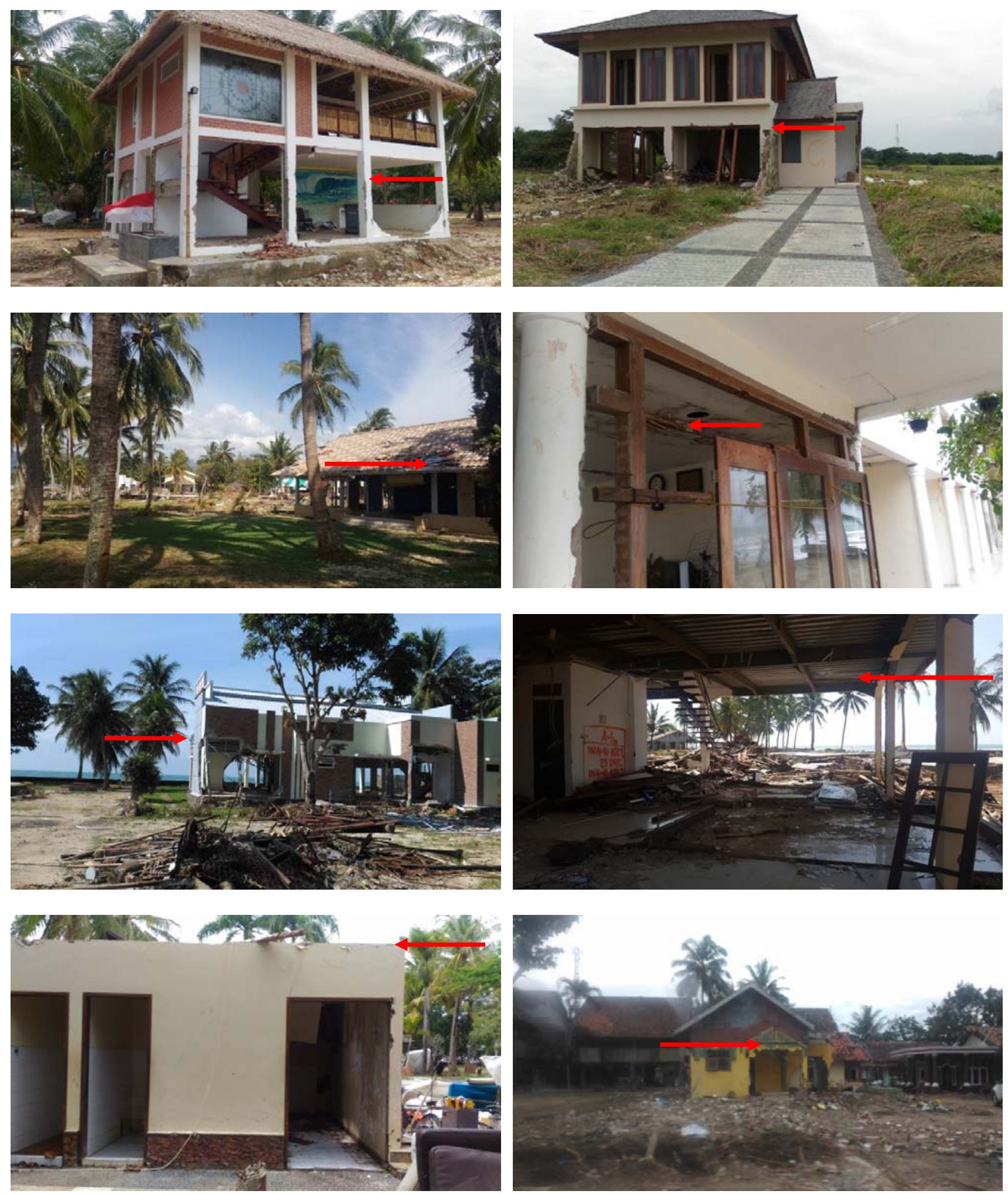

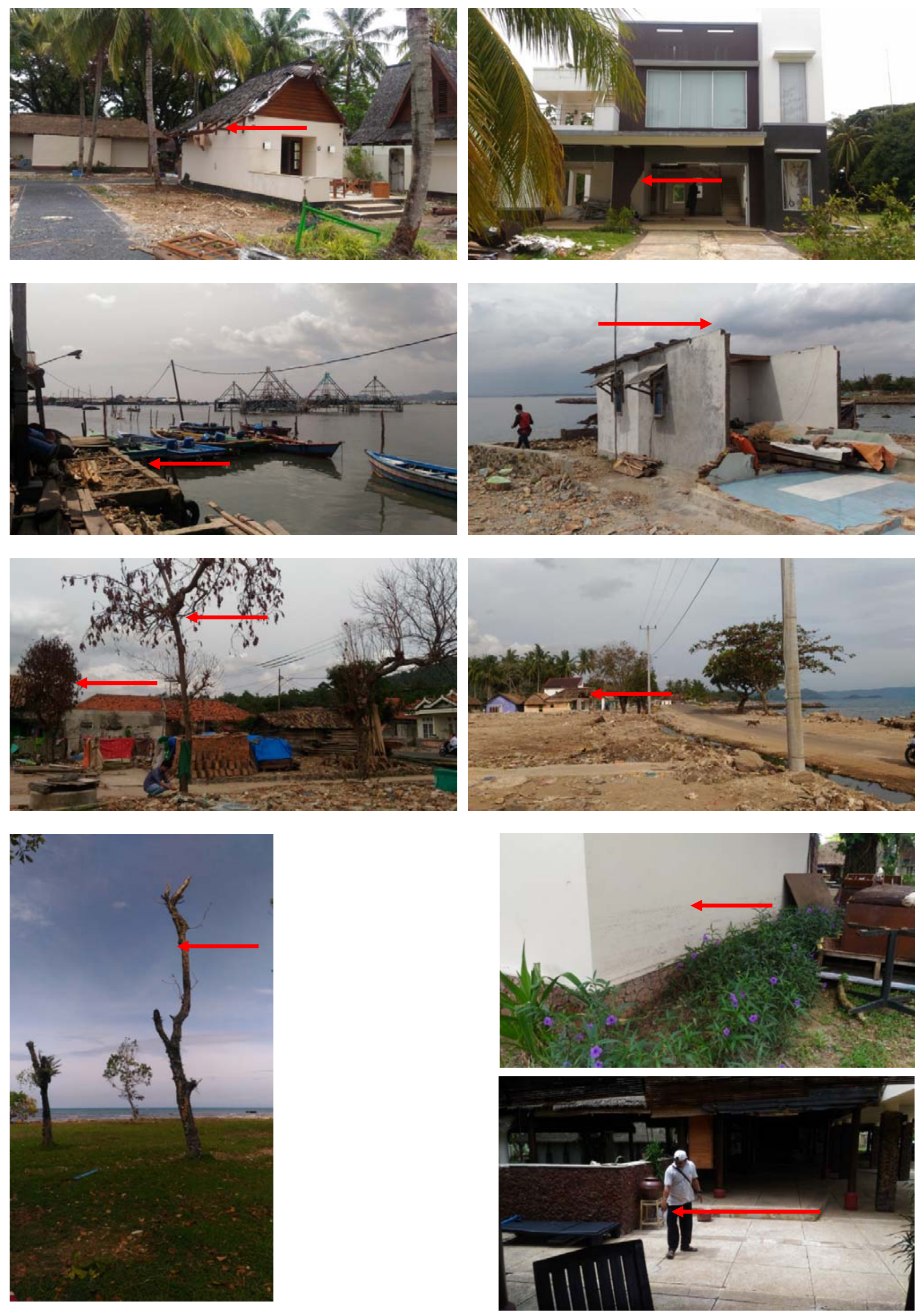
Interview with eyewitnesses
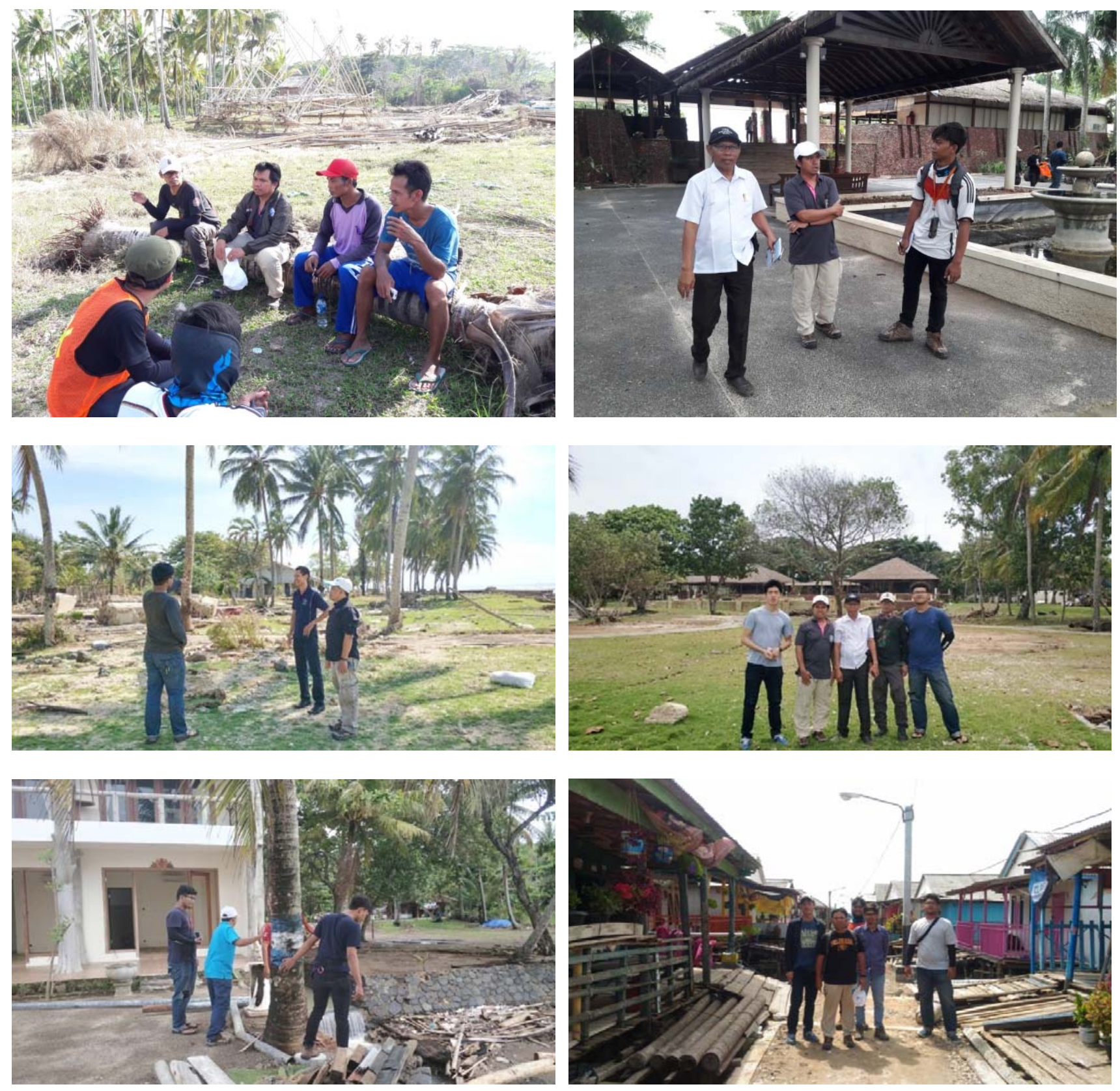